\section{S.O.S: Prepared for the Emergency?}

Lic. Maria Cristina Saenz; Doctor Oreste J. Licursi

Argentinian Red Cross, ARGENTINA

Introduction: This experience indicates that discoveries in medical science and psychology applied to training, especially of volunteers, helps to alleviate the effects of stress in an emergency with an objective of preventing disasters, especially as applied to managing human resources. Objectives: Qualify persons to react in psychosocial crisis that are produced in an emergency or disaster, and to understand the extent of the psychological and multiple organic stresses on persons affected. It also sought to prepare the professionals of emergency brigades and their helpers, and to inform and motivate the population in general, to obtain an answer in cases of emergencies. It involved the training of qualified volunteers of governmental and non governmental institutions (schools, airline companies, foundations, etc.).

Methods: The people in charge of qualifying and some people that are qualified developed some projects in this field: 1) the control of clinical parameters has been done in a group of works that have been dedicated to medical emergencies. The daily evaluation of blood pressure and heart rate showed an increase in relation to the amount of time that has passed and the level of responsibility; 2) organization in a local emergency for floods with 39 centers for the victims of this phenomenon. Three mobile medical attention centers have been developed and used in an emergency that occurred in a city of 650,000 inhabitants, with 5,500 people located in risk zones, who had to leave their houses; and 3) The experiences of patients and medical personnel in surgical and intensive care areas were obtained.

Conclusions: 1) There is a correlation between the level of knowledge and training and the alterations in the clinical parameters observed. The emotional training in these situations, improves professional efficiency; 2) It is necessary for human and technical resources to be prepared before emergencies and disasters occur in order for them to be effective after the events; 3) This leads to the concept that natural phenomena (tornadoes, floods, etc.) are not disasters in themselves; rather, the events become disasters if people do not know how to manage them; 4) Therefore, it is of vital importance that the community, government, and non-governmental agencies coordinate their efforts; 5) There is a need to make agencies that take part in the rescue work and the general population be made aware of psychosocial support and the importance of disaster drills so that they know the steps to take in an emergency; and 6) We succeeded in justifying the need for a training programme on psychosocial support.

Keywords: disasters; drills; emergencies; events; preparedness; psychosocial; rescue; support; volunteers

E-mail: Jlicuri@intramed.net or Mari saenez@hotmail.com
Cost-Benefit of Point-of-Care Blood Gas Analysis Kyle Stevens, EMAII; ${ }^{1}$ Greg Grant, MD, FRCPC; ${ }^{2}$ Andrew J Macnab, MD, FRCPC, , Faith Gagnon, HBSc; Robert Noble, EMAIII; ${ }^{1}$ Charles Sun, MD, FRCPC ${ }^{4}$

1) British Columbia Ambulance Service and University of British Columbia Faculty of Medicine, Vancouver, British Columbia; 2) Department of Medicine, University of British Columbia, Vancouver, British Columbia; 3)Department of Pediatrics, University of British Columbia, Vancouver, British Columbia; 4) British Columbia Ministry of Health, CANADA

Introduction: Point-of-care testing allows laboratory tests to be independent of hospital-based resources and power. We studied whether the iSTAT Portable Clinical Analyzer was cost-effective in managing ventilated pediatric patients prior to inter-hospital transport.

Methods: Data were collected prospectively: 1) when blood gas analysis was requested; 2) the need to call-in technicians; and 3) waiting times for results. Cost-efficacy calculations were based on: 1) 3 minutes to obtain a result using the iSTAT (unit cost $\$ C D N 8,000$ ); 2) lab technician call-back; paramedic overtime; and 3) cost of charter aircraft wait time.

Results: Among 46 patients, blood gases were required on 35. Technicians were called-in for 17 (49\%). Time waiting to obtain laboratory gases was 526 minutes compared with a calculated 105 minutes using point-of-care testing. Cost-saving on technician call-back $(\$ 1,530)$, paramedic overtime $(\$ 690)$, and aircraft time waiting charges $(\$ 2,000)$ totaled $\$ 4,220$. Cost of point-of-care equipment could have been recouped in 101 patients if aircraft charges applied or 192 patients if no aircraft costs were included. In 11 cases, ventilator adjustments were made during transport, and in 6 patients, point-of-care testing would have been used to optimize transport care.

Conclusion: The present study indicates that this technology is cost-effective and can reduce stabilization times. The technology would be ideal for medical management during disasters.

Keywords: analysis; blood gases; cost; efficacy; point-of-care; savings; transport; ventilation (assisted)

E-mail: amacnab@cw.bc.ca 